\begin{tabular}{|l|c|} 
Proceeding of the $9^{\text {th }}$ ICEE Conference 3-5 April 2018 & NRA \\
Military Technical College \\
Kobry El-Kobbah, \\
Cairo, Egypt
\end{tabular}

NRA-5

\title{
Characterization and Assessment of Fast Neutron Attenuation Properties of Developed Concrete Mixes at Different Temperatures
}

\author{
Moamen G. El-Samrah ${ }^{1}$ and Mohamed A.E. Abdel-Rahman ${ }^{1}$
}

\begin{abstract}
Concrete is regarded as one of the most proper materials that can be used in many applications concerning with shielding against gamma radiation and neutrons since they are the most penetrating radiation. In this study three different concrete mixes were prepared with three different types of coarse aggregates: barite, goethite and dolomite. Fine aggregates are selected to be local sand and limonite. Additives used are silica fume (SF) and fly ash (FA) by replacement of the total cement weight. To examine the performance of these concrete mixes to be used as radiation shielding concretes, a set of physical, mechanical and radiation attenuation measurements were carried out. Such investigations include compressive strength, slump test, bulk density as well as gamma ray and fast neutron attenuation properties for the prepared mixes at room temperature and after heating up to $450^{\circ} \mathrm{C}$. The experimental results revealed that all concrete mixes; barite concrete (labeled Ba.C), goethite concrete (labeled Go.C) and dolomite concrete (labeled Do.C) show adequate physical and mechanical properties that successfully classifying them as high performance concretes. In addition $\mathrm{Ba}$. $\mathrm{C}$ has the higher $\gamma$-ray attenuation coefficients. For fast neutron attenuation measurements, it was found that Go.C mix has the highest integrated fast neutron removal macroscopic cross section $(\Sigma)$ ,emitted from ${ }^{252} \mathrm{Cf}$, at room temperature and thus the corresponding minimum required HVL. The Ba.C mix came in the second place following the Go.C mix. Heating up to $450^{\circ} \mathrm{C}$, fast neutron attenuation properties of Go.C mix were fully deteriorated because of certain reasons that are illustrated in this study.
\end{abstract}

\section{Keywords:}

Radiation shielding concrete, TGA, Heating effect, Half value layer (HVL), Mass attenuation coefficient $\left(\mu_{\mathrm{m}}\right)$ and integrated fast removal cross section $(\Sigma)$

${ }^{1}$ Nuclear Engineering Department, Military Technical College, Cairo, Egypt 


\section{Military Technical College \\ Kobry El-Kobbah, Cairo, Egypt}

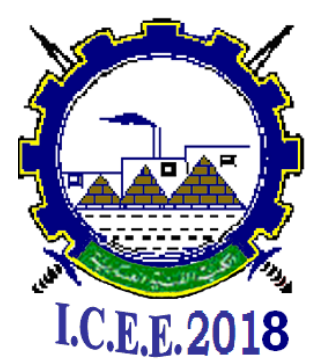

9 $\frac{\text { th }}{\text { International Conference }}$ on

Chemical \& Environmental Engineering

3-5 April 2018

\section{Introduction}

In nuclear shielding applications, the most important to be regarded is the indirect ionizing radiation ( $\gamma$-rays and neutrons) since they have high penetrating power and considerable ranges. On the other hand, the direct ionizing radiation $(\alpha, \beta)$ has small external hazard due to their small ranges in the transferring media and their weak penetration abilities so, they almost lose their full energies in quite small ranges [1]. Hence any shield that can attenuate indirect ionizing radiation to small level will automatically attenuate the others to tiny or ignored values. In attenuating gamma rays, elements with high atomic number are preferred thus dense materials are required like steel and lead for example. However, in attenuating neutrons, especially fast neutrons, light elements like hydrogen and oxygen are required and as a conclusion from the former, the shielding barrier should have high density and in the same time high hydrogen or light elements content so, considering these different demands, the optimum shielding barrier that can be used is concrete especially heavy weight concrete which achieves a good compromise between the high density and high hydrogen content [2]. The selection of local suitable aggregates and additives is very important for preparing radiation shielding concrete to achieve the optimum properties [3]. Some of the widely used aggregates in preparation of radiation shielding concrete are galena, magnetite, barite, limonite, goethite, serpentine, colemanite and some of artificial synthetic aggregates like steel punching, iron fibers, iron shots, steal slag and boron frits $[4,5]$. It is essential that aggregates used in radiation shielding concrete must be inert with respect to alkalis and have good physic-mechanical properties to obtain adequate mix [2].

The main objective of this study was to investigate the physical, mechanical and radiation attenuation properties of the different prepared concrete mixes and the effect of heating on their attenuation properties against fast neutrons in order to assess durability and effectiveness of these shielding barriers even if at higher temperature in case of any accident that may occur. For this purpose, three different concrete mixes were prepared from naturally occurring ores using dolomite, barite and goethite, while local sand and limonite ore were selected to be used as fine aggregates. The specimens used in this study to cover the physic-mechanical, gamma rays and fast neutrons attenuation properties have two shapes, standard cubes with dimensions $(10 \mathrm{~cm} \times 10 \mathrm{~cm} \times 10 \mathrm{~cm})$, standard cylinders (with dimensions $10 \mathrm{~cm}$ diameter and $20 \mathrm{~cm}$ length) that were cut to different thicknesses. 
Military Technical College

Kobry El-Kobbah, Cairo, Egypt

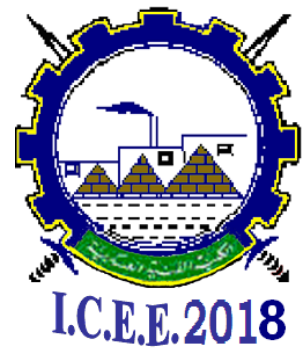

$9^{\text {th }}$ International Conference on

Chemical \& Environmental

Engineering

3-5 April 2018

\section{Methodology of research}

\subsection{Materials}

In this study, the aggregates selected were chosen mainly to enhance and develop the attenuation properties against gamma rays and fast neutrons and in the same time satisfy the basic requirements of construction applications. For this purpose, three different concrete mixes were prepared from naturally occurring ores, goethite $[\alpha-\mathrm{FeO}(\mathrm{OH})]$, barite $\left[\mathrm{BaSO}_{4}\right]$ and limonite $\left[\mathrm{Fe}_{2} \mathrm{O}_{3} \cdot \mathrm{nH}_{2} \mathrm{O}\right]$ all obtained from El-Bahariya Oasis, Western Desert, Egypt, dolomite $\left[\mathrm{CaMg}\left(\mathrm{CO}_{3}\right)_{2}\right]$ and local sand, obtained from Helwan, Egypt. The cement used in this study was Portland blast furnace slag cement CEM/B-S $42.5 \mathrm{~N}$ (labeled PBFSC) which is compatible with ASTM C-150 [6], from El-Aamryah Cement Company, Egypt. The additives used are fly ash (FA) class F, silica fume (SF) and super plasticizer Sikament-NN (type G) all from Sika Company, El-Obour, Egypt. All aggregates were sieved in order to get coarse aggregates in the range 5-20 $\mathrm{mm}$ and fine aggregates with particle size in the range 0.3-5 $\mathrm{mm}[7]$. Some important physicmechanical properties of aggregates are given in Table 1. Elemental analysis was performed for cement, additives and aggregates using XRF spectrometer as given in Table 2

\subsection{Thermal gravimetric analysis (TGA)}

Thermal gravimetric analysis (TGA) for limonite and goethite ores was performed using Instrument TGA Q500 V20.10 Build 36. Samples were heated from $30^{\circ} \mathrm{C}$ to $800^{\circ} \mathrm{C}$ at heating rate $10^{\circ} \mathrm{C} / \mathrm{min}$. Sample weight used in each test ranged from $5.9 \mathrm{mg}$ to $6.66 \mathrm{mg}$.

\subsection{Mix proportions}

Three different concrete mixes were prepared using goethite, barite and dolomite as coarse aggregates. Fine aggregates used in all mixes (except Do.C mix) were (50\% local sand $-50 \%$ limonite) in addition to $10 \%$ silica fume (SF) and $10 \%$ fly ash (FA) as a partial replacement from the total cement content. The three concrete mixes were prepared according to the American Concrete Institute method (ACI) of absolute volumes [8]. Mix proportions per $1 \mathrm{~m}^{3}$ for the prepared concrete mixes are given in Table 3.All aggregates used in this study were used in saturated surface dry form to eliminate the effect of water absorption during mixing in order to evaluate the real effect of aggregates on concrete mixes properties [2]. The water to cement ratio for all mixes were selected to be 0.43 . 
Military Technical College

Kobry El-Kobbah,

Cairo, Egypt

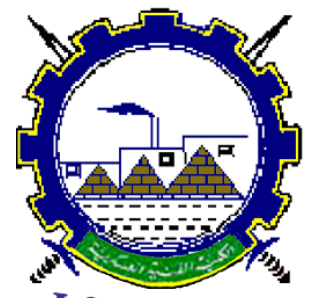

I.C.E.E.2018 $9^{\text {th }}$ International Conference

on

Chemical \& Environmental

Engineering

3-5 April 2018

\subsection{Mixing, curing and investigated specimens}

The strength of concrete can be affected by several factors, in this study the main concern is with the effects of the change in concrete constituents such as using different aggregates and their effects on concrete strength and other mechanical and radiation attenuation properties of the studied concrete mixes [9]. All samples were placed at room temperature and were cured for 28 days in curing tanks under water until testing date. The curing water was changed every 7 days. The specimens prepared in this study have two geometrical shapes as given before.

\subsection{Slump test}

The slump test is an indication on the behavior of a compacted inverted cone of fresh concrete under the action of gravity. It measures the consistency or the wetness of concrete. It is also a simple method to evaluate the workability of the prepared concrete. The test was performed according to ASTM 143[10].

\subsection{Bulk density}

For concrete, expressing the density in kilograms per cubic meter is widely common when aggregates are to be actually batched by volume and here the density to be calculated is called bulk density. The bulk density for hardened concrete mixes was performed according to ECCS 203-2001code [11].

\subsection{Compressive strength}

The compressive strength of concrete is usually determined by applying a uniformly distributed increasing compression load on a cubic specimen using suitable testing equipment until failure. The testing equipment used for this test is $2000 \mathrm{KN}$ universal machine. The test was performed using a set of three cubic specimens $\left[10 \times 10 \times 10 \mathrm{~cm}^{3}\right]$ for each concrete mix at curing age (28 days) and the formula used for calculating compressive strength of concrete is:

$$
\sigma_{\mathrm{c}}=\mathrm{P} / \mathrm{A} \quad \mathrm{Kg} / \mathrm{cm}^{2}
$$

Where, $\mathrm{P}$ is the maximum load and $\mathrm{A}$ is the surface area of the cubic specimen $(=100$ $\mathrm{cm}^{2}$ ).

The compressive strength at 90 days was estimated using the following general equation:

$$
\left(\sigma_{\mathrm{c}}\right)_{\mathrm{t}}=\frac{\mathrm{t}}{\mathrm{a}+\mathrm{bt}} \times\left(\sigma_{\mathrm{c}}\right)_{28}
$$




\section{Military Technical College \\ Kobry El-Kobbah, Cairo, Egypt}

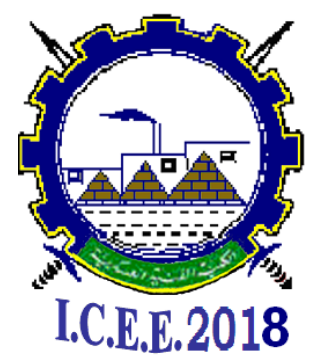

$9^{\text {th }}$ International Conference on

Chemical \& Environmental Engineering

3-5 April 2018

Where: $\left(\sigma_{c}\right)_{t}$ and $\left(\sigma_{c}\right)_{28}$ are the compressive strength of concrete at any age $t$ days and at 28-days, respectively. Both $a$ and $b$ are the coefficients which are varied for different cements and curing conditions. According to ACI 209/71 standard, this equation was obtained as a result of a study of concrete strength versus time with different types of concrete [12]. The constants $a$ (days) and $b$ both are related to the characteristics of the used mix design and curing conditions and they could be determined by solving two simultaneous equations at two different ages using previous experimental work which was suitable and agreeable with the mixes used in this study $[2,13]$.

\subsection{Gamma rays attenuation measurements}

In this study, cylindrical samples of dimensions $20 \mathrm{~cm}$ in length and $10 \mathrm{~cm}$ in diameter were prepared for all concrete mixes and then cut to different thicknesses. The gamma ray sources used in these tests are Ba-133, Cs-137 and Co-60 with four gamma lines and their specifications are given in Table 4.

The gamma rays of the sources were detected and measured using NaI(Tl), 3"x3", scintillation detector with multichannel analyzer using software (UCS-30) version 1.1.06 USB, Spectrum Technique 2010. To achieve a good geometry condition, the gamma source was placed inside $3 \mathrm{~cm}$ lead holder (source collimator) with an aperture of $3 \mathrm{~mm}$ in diameter, while the scintillation detector had been surrounded by blocks of lead (detector collimator) to prevent scattered gamma rays from entering the detector to get a more precise measurements [14].

Mass attenuation coefficient and half value layer (HVL) for each concrete mix were obtained from the following equations [2].

$$
I_{x}=I_{o} e^{-\mu_{m}(\rho x)}, H V L\left(x_{1 / 2}\right)=\frac{\ln 2}{\mu}
$$

Where: $I_{x}$ is the intensity after the shielding, $I_{0}$ is the intensity without shielding, $\mu_{m}$ is the mass attenuation coefficient $\left(\mathrm{cm}^{2} / \mathrm{g}\right), \mu$ is the linear attenuation coefficient and $\rho \mathrm{x}$ is the density thickness $\left(\mathrm{g} / \mathrm{cm}^{2}\right)$.

\subsection{Fast neutrons attenuation measurements}

The study of the neutron attenuation properties is complicated because of the neutron wide energy spectra and their different modes of interaction with the investigated barriers (shielding materials) as well as the production of secondary gamma rays with different energies depending on the nuclear reactions occur between the incident neutrons and the different constituent atoms in the investigated barriers. This is in addition to the 


\section{Military Technical College \\ Kobry El-Kobbah, Cairo, Egypt}

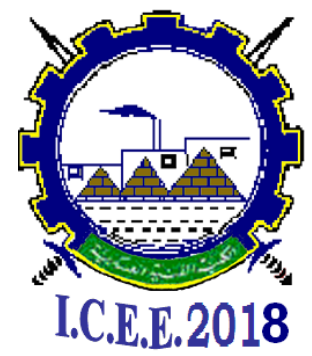

$9^{\text {th }}$ International Conference on

Chemical \& Environmental Engineering

3-5 April 2018

attenuation modes like inelastic scattering and radiative capture. In this study, fast neutrons and total gamma rays attenuation properties of the prepared concrete mixes were performed at normal temperature and after heating up to $450^{\circ} \mathrm{C}$ both with the same way by measuring the transmitted spectra of neutrons and total gamma rays produced primary from the source and during the interaction of neutrons with the different components of the samples.

The integrated fast neutrons removal macroscopic cross section $(\Sigma)$ for each mix, the linear attenuation coefficient $(\mu)$ for the total gamma rays (primary in addition to secondary) and the Half value layer (HVL) for each concrete mix for both fast neutrons and total gamma rays were obtained from the following equations [1].

$$
I_{x}=I_{0} e^{-\Sigma x} \quad, I_{x}=I_{0} e^{-\mu x} \quad, H V L_{n \text { or } \gamma}=\frac{\ln 2}{(\Sigma) \text { or }(\mu)}
$$

For carrying out neutron and total gamma rays measurements, a collimated beam of ${ }^{252} \mathrm{Cf}$ neutron source with an initial activity $100 \mathrm{mCi}$, Table 5, and organic scintillation counter with stilbene crystal with dimensions $4 \mathrm{~cm}$ for the diameter and $4 \mathrm{~cm}$ for the crystal thickness and photomultiplier tube were used. Pulse shape discriminating technique based zero cross over method was used to discriminate between neutron and gamma pulses.

The distance between the front of the detector and the source is $21 \mathrm{~cm}$. Source collimator is made from lead and cylindrical in shape with an outer radius of $3.5 \mathrm{~cm}$ and an inner one of $1.5 \mathrm{~cm}$. Detector collimator is also made from lead used as slabs of thickness 10 $\mathrm{cm}$ surrounded the detector from all sides. These lead collimators were used to eliminate the side scattered radiation especially the highly energetic gamma rays that produced via the interaction of escaped neutrons with the high $(Z)$ atoms in the walls of the lab thus enhancing the discrimination capability of the discriminating techniques. The geometry was fixed during all measurements. The setup and the associated electronics are displayed in Figure 1.

\section{Results and Discussion}

\subsection{Thermal gravimetric analysis}

\subsubsection{TGA for limonite ore}

Limonite or as called hydrated hematite $\mathrm{Fe}_{2} \mathrm{O}_{3} \cdot \mathrm{nH}_{2} \mathrm{O}$ in general is an intermediate phase during goethite transformation into hematite [15]. 


\section{Military Technical College \\ Kobry El-Kobbah, Cairo, Egypt}

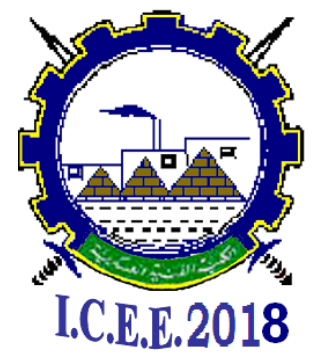

$9^{\text {th }}$ International Conference on

Chemical \& Environmental Engineering

3-5 April 2018

Figure 2 shows two dehydration steps with average temperatures at $99^{\circ} \mathrm{C}$ and $276^{\circ} \mathrm{C}$ were observed. The first step was with temperature range $\left(49^{\circ} \mathrm{C}-150^{\circ} \mathrm{C}\right)$ and weight loss about $2.5 \%$. The second step was the main with temperature range $\left(200^{\circ} \mathrm{C}-352^{\circ} \mathrm{C}\right)$ and weight loss about $5.5 \%$. This curve or pattern of TGA corresponded probably to the bulk composition of $\mathrm{Fe}_{2} \mathrm{O}_{3} \cdot 2 \mathrm{H}_{2} \mathrm{O}$ [15]. The total weight loss was $8 \%$ of the total sample weight.

\subsubsection{TGA for goethite ore}

From the TGA pattern as shown in Figure 3, one main step of weight loss about $8.5 \%$ in the temperature range $\left(221^{\circ} \mathrm{C}-341^{\circ} \mathrm{C}\right)$ with average temperature $281^{\circ} \mathrm{C}$ was observed for the ore. Generally, this TGA pattern represents goethite - hematite transformation:

$$
2 \alpha \mathrm{FeOOH} \rightarrow \mathrm{Fe}_{2} \mathrm{O}_{3}+\mathrm{H}_{2} \mathrm{O}
$$

The average temperature is usually at $385^{\circ} \mathrm{C}$ for highly crystalline goethite and for amorphous goethite the transformation range and average temperature are always located at lower values and That indicated the amorphous nature of the used ore [16].

\subsection{Slump test results}

The results showed that the slump values of the prepared concrete mixes ranged from 6 $\mathrm{cm}$ to $10 \mathrm{~cm}$ as shown in Table 5, which means that all mixes were accepted from the workability point of view [10]. The highest slump value obtained with Do.C and the lowest value obtained with Go.C mix. These results can be related mainly to the differences in the water absorption ratios of the different aggregates in addition to the high specific gravity values for the used coarse aggregates except for dolomite used in Do.C mix (see Table 6).

\subsection{Bulk density}

The bulk densities for different concrete mixes are given in Table 7. The results obtained were predictable as the bulk density of the prepared concrete is directly proportional to the specific gravity of the aggregates used in the mix design (see Table 2); therefore, Ba.Cmix were found to have the highest value of bulk density. Ba.C and Go.C can be classified as heavy density concretes because both were found to have bulk density values more than $2600 \mathrm{~kg} / \mathrm{m}^{3}$ [17]. On the other hand Do.C approached to be heavy weight concrete as its density was $2570 \mathrm{~kg} / \mathrm{m}^{3}$.

\subsection{Compressive strength results}



Military Technical College
Kobry El-Kobbah, Cairo, Egypt

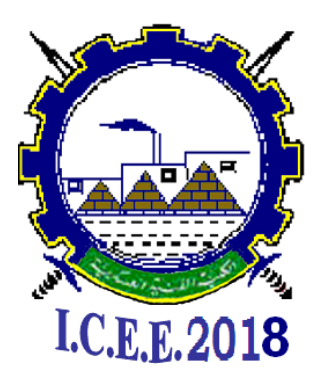

$9^{\text {th }}$ International Conference on

Chemical \& Environmental

Engineering

3-5 April 2018

\subsubsection{Compressive strength values at room temperature}

After curing for 28 days, the concrete mixes gained the most of their strength because of the formation of the hydration products and the domination of hydrated calcium silicate (C-S-H gel) among these hydration products. The compressive strength of all concrete mixes in this study was higher than that of traditional concrete. Using Portland blast furnace slag cement with high content was one of the reasons that lead to the concrete mixes high strength also the addition of fly ash and silica fume participated in the development of the strength of the mixes due to their good filling effect. The compressive strength of the different concrete mixes at 28 days and 90 days (estimated) is plotted in Figure 4. The results obtained revealed that Do.C was significantly higher than the other two mixes Go.C and Ba.C and the differences could be attributed to the physicmechanical properties of the coarse and fine aggregates used (see Table 2). The use of limonite as a portion of the fine aggregates was due to its good shielding properties but it had a bad effect on the strength of the mixes because its high water absorption value. The relative small crushing value and high specific gravity (4.04) had a good effect on gaining strength in Go.C mix but on the other hand its high water absorption value $(13.5 \%)$ minimize this good effect. The high crushing value of barite $(63.3 \%)$ had a significant bad effect on the Ba.C strength even if its low water absorption value (1.5\%) and high specific gravity (4.4). Using sand only as fine aggregate beside dolomite as coarse aggregate in Do.C mix had a good effect on the strength due to their low water absorption values $(0.4 \%, 0.7 \%)$ respectively, and the convergence in the specific gravity of both of them which had a great effect on strengthening the physical bonds between them and also with the binder.

\subsubsection{Compressive strength values at elevated temperatures}

The results of compressive strength at different temperatures for the prepared concretes are shown in Figure 5.

For the three prepared mixes, regular decrease was observed in the compressive strength after heating up to $100^{\circ} \mathrm{C}$ and that is because of vaporization of the residual mixing water. Then, in the range of $\left(100^{\circ} \mathrm{C}-200^{\circ} \mathrm{C}\right)$ the decrease continued for Do.C mix but the decrease was minimized for Go.C concrete mix. However, a large drop was observed in the compressive strength for Ba.C mix.

Finally, in the range of $\left(200^{\circ} \mathrm{C}-450^{\circ} \mathrm{C}\right)$ the rate of the decrease in compressive strength was minimized for Do.C and Ba.C mixes and at the final point the compressive strength for Ba.C concrete mix became lower than $20 \mathrm{MPa}$ which is refused from the construction point of view. For Do.C mix the compressive strength value was higher than $25 \mathrm{MPa}$ and that is accepted. On the other hand, large drop was noticed in the compressive strength for Go.C mix and the reason could be due to the dehydroxylation of goethite $(\alpha \mathrm{FeOOH})$ 

Military Technical College
Kobry El-Kobbah, Cairo, Egypt

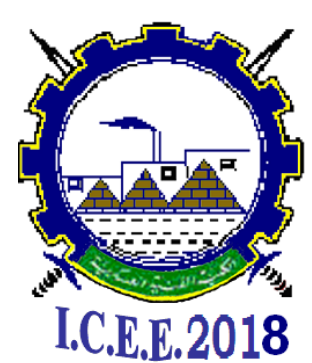

$9^{\text {th }}$ International Conference on

Chemical \& Environmental Engineering

3-5 April 2018

and transformation into ferric oxide $\mathrm{Fe}_{2} \mathrm{O}_{3}$ and $\mathrm{H}_{2} \mathrm{O}$. At the final point, compressive strength for Go.C mix became lower than $20 \mathrm{MPa}$ (like Ba.C mix) and that is also refused from the construction point of view.

\subsection{Gamma rays attenuation measurements}

The main target of this part was to study gamma rays attenuation properties for the prepared mixes used in this study and to determine the best mix among the three mixes. The obtained values of mass attenuation coefficient $\left(\mu_{\mathrm{m}}\right)$ and HVL for all mixes are shown in Table 8.

From the obtained results we found that Ba.C mix has the greatest linear attenuation coefficient against gamma rays and thus the corresponding minimum required HVL for these energies. The reason could be due to the high atomic number of barium (56) which is the effective element in barite that was used as coarse aggregate in Ba.C mix in addition to the high specific gravity for Ba.C mix (2.963). The priority of Ba.C is clear and obvious especially at low and intermediate energies because of the significant contribution of photoelectric effect while at higher energies Go.C gamma rays attenuation properties become so close to those of $\mathrm{Ba}$.C mix because in this range of energies there is no notable contribution of photoelectric effect and the attenuation occurs mainly due to Compton scattering and pair production knowing that specific gravity of Ga.C mix (2.906) is very close to that of Ba.C mix. On the other hand, Do.C mix is in the last order because of its low density and the absence of the effective elements like barium or iron.

\subsection{Fast neutrons attenuation properties at normal temperature}

All values of integrated fast removal macroscopic cross section ( $\Sigma$ ), linear attenuation coefficient (for total gamma rays) and half value layer (HVL) for the prepared mixes for fast neutrons and total gamma rays attenuation measurements are shown in Table 9.

Based on the results obtained, Go.C mix was found to have the greatest integrated fast neutrons macroscopic removal cross section $(\Sigma)$ against neutrons emitted from ${ }^{252} \mathrm{Cf}$ radioactive source at room temperature and thus the corresponding minimum required HVL while Ba.C mix came in the second order. The reason could be due to effective elastic scattering because of the high hydrogen content that contained in goethite $(\alpha \mathrm{FeO} . \mathrm{OH})$ which was used as coarse aggregate and limonite $\left(\mathrm{Fe}_{2} \mathrm{O}_{3} \cdot \mathrm{nH}_{2} \mathrm{O}\right)$ which used as fine aggregate. In case of Ba.C mix, the high atomic number of barium (56) which is the effective element in barite that was used as coarse aggregate in Ba.C mix could be the main reason in having good attenuating properties against fast neutrons emitted from ${ }^{252} \mathrm{Cf}$ neutron source because of the inelastic scattering of fast neutrons with barium atoms. 


\section{Military Technical College \\ Kobry El-Kobbah, Cairo, Egypt}

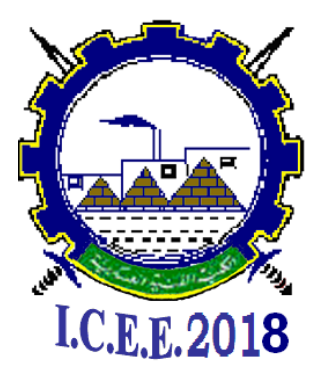

$9^{\text {th }}$ International Conference on

Chemical \& Environmental Engineering

3-5 April 2018

On the other hand, for the total gamma rays include primary gamma photons emitted from ${ }^{252} \mathrm{Cf}$ neutron source and secondary gamma rays produced during interaction of neutrons with the samples, it was found that the Ba.C concrete mix has the greatest total linear attenuation coefficient $(\mu)$ at room temperature and thus the corresponding minimum required $\mathrm{HVL}$.

\subsection{Fast neutrons attenuation properties at elevated temperatures}

After heating all mixes at $100^{\circ} \mathrm{C}, 200^{\circ} \mathrm{C}$ and $450^{\circ} \mathrm{C}$, the results shown in Figure 6 revealed significant changes and differences between studied mixes in the priority of usage in attenuating fast neutrons at higher temperatures.

At first, after heating up to $100^{\circ} \mathrm{C}$, all concrete mixes were found to be in the same order with observable decrease in the integrated fast neutrons removal macroscopic cross section $(\Sigma)$ values that could be attributed to the evaporization of the residual mixing or additive water. Secondly, at $200^{\circ} \mathrm{C}$, the above mentioned order was changed and the Do.C mix became in the second level after Go.C mix because this point can be considered as the start edge of the transformation of limonite $\left(\mathrm{Fe}_{2} \mathrm{O}_{3} \cdot \mathrm{nH}_{2} \mathrm{O}\right)$ to ferric oxide $\left(\mathrm{Fe}_{2} \mathrm{O}_{3}\right)$ during a dehydration process and as mentioned before Do.C mix is the only concrete mix that had no limonite in its mix design. Finally, after raising heating temperature up to $450^{\circ} \mathrm{C}$, the Go.C concrete mix attenuation properties against fast neutrons were deteriorated and the reason could be related to the dehydroxylation of goethite $(\alpha \mathrm{FeOOH})$ with a great weight loss and the same with limonite as mentioned earlier and that put Do.C mix in the first level at this point.

On the other hand, for total gamma rays, after heating at $100^{\circ} \mathrm{C}, 200^{\circ} \mathrm{C}$ and $450^{\circ} \mathrm{C}$, the results shown in Figure 7 also revealed notable results. At the begining, after heating up to $100^{\circ} \mathrm{C}$, there was no observable decrease in the total linear attenuation coefficient $(\mu)$ values for all concrete mixes that the evaporization of the residual mixing or additive water not make a difference in attenuating gamma rays. Then, at $200^{\circ} \mathrm{C}$ there was observable decrease in the total linear attenuation coefficient $(\mu)$ values for all concrete mixes and it was observed that the Ba.C concrete mix still have the highest attenuation coefficient. This observable decrease could be related to the notable weight loss for all mixes at this point. Finally, Go.C mix attenuation properties against total gamma rays deteriorated and became in the last order and the reason could be due to the transformation of goethite $(\alpha \mathrm{FeOOH})$ and limonite $\left(\mathrm{Fe}_{2} \mathrm{O}_{3} \cdot \mathrm{nH}_{2} \mathrm{O}\right)$ into ferric oxide $\left(\mathrm{Fe}_{2} \mathrm{O}_{3}\right)$ and $\mathrm{H}_{2} \mathrm{O}$ with a great weight loss and great production of voids. 


\section{Military Technical College \\ Kobry El-Kobbah, Cairo, Egypt}

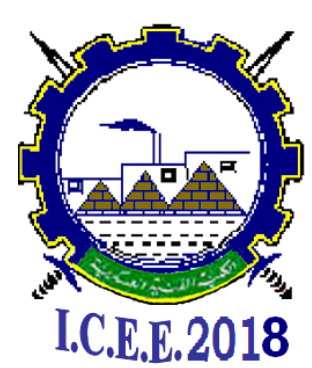

$9^{\text {th }}$ International Conference on

Chemical \& Environmental Engineering

3-5 April 2018

\section{Conclusion}

Slump values for all mixes were obtained fulfilling the requirements (higher than $5 \mathrm{~cm}$ ) which means that all mixes were accepted from the workability point of view.

The results gained by the bulk density test showed that Ba.C mix has the highest bulk density among the investigated concrete mixes. Furthermore it should be noted that Ba.C and Go.C can be classified as heavy weight concrete because both mixes showed bulk density values more than $2600 \mathrm{~kg} / \mathrm{m}^{3}$. On the other hand Do.C approached to be heavy weight concrete as its density was $2570 \mathrm{~kg} / \mathrm{m}^{3}$.

The compressive strength results of such concrete mixes was higher than that of traditional concrete, such results revealed that Do.C had significantly higher compressive strength than the other two mixes (Go.C and Ba.C mixes) and the differences could be attributed to the physic-mechanical properties of the coarse and fine aggregates used.

From the chemical XRF analysis, it was obviously clear that the used aggregates (except dolomite) had high content of the desired effective elements like Iron $(\mathrm{Fe})$ or Barium $(\mathrm{Ba})$ or both of them, as in the case of barite ore, which was the main reason for the high density of the aggregates and thus the concrete mixes. Also using goethite and limonite with their high light element content had notable effect on fast neutron attenuation properties.

Due to the results obtained from gamma rays attenuation measurements, it was observed that Ba.C concrete mix have the greatest linear attenuation coefficient against gamma rays.

Concerning the fast neutrons and total gamma attenuation measurements and based on the results obtained, it was found that Go.C mix have the greatest integrated fast neutrons removal macroscopic cross section $(\Sigma)$ emitted from ${ }^{252} \mathrm{Cf}$ at room temperature and thus the corresponding minimum required HVL. The Ba.C concrete mix came in the second order. Ba.C mix was found to have the highest total linear attenuation coefficient $(\mu)$ at room temperature and thus the corresponding minimum required $\mathrm{HVL}$.

After heating concrete mixes up to $450^{\circ} \mathrm{C}$, a significant changes and differences between the investigated mixes in the priority of usage for attenuating fast neutrons were observed. At first, after heating up to $100^{\circ} \mathrm{C}$, all concrete mixes was found to have the same order of observable decrease in the integrated fast neutrons removal macroscopic cross section $(\Sigma)$ values. Secondly, at $200^{\circ} \mathrm{C}$, the above mentioned order was changed and the Do.C mix became in the second level after the Go.C mix. Finally, after raising heating temperature up to $450^{\circ} \mathrm{C}$, the Go.C mix attenuation properties against fast neutrons and total gamma were fully deteriorated. 
Military Technical College Kobry El-Kobbah, Cairo, Egypt

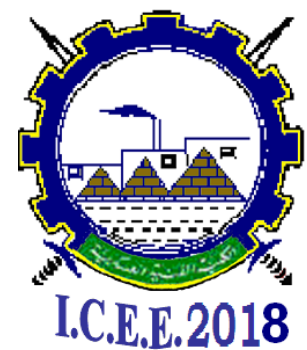

$9^{\text {th }}$ International Conference on

Chemical \& Environmental Engineering

3-5 April 2018

\section{References}

[1] J.R.Lamarsh, and A.J. Baratta, Introduction to Nuclear Engineering, 3rd edition, Prentice Hall, USA, 2001.

[2] A.S. Ouda, , Development of high-performance heavy density concrete using different aggregates for gamma-ray shielding, HBRC Journal, 2014.

[3] M. Morsy, An Investigation of Some Properties of Heavy Weight Concrete Mixes in Egypt, HPRC, 1990.

[4] S. Alhajali, S. Yousef, and B. Naoum, Appropriate concrete for nuclear reactor shielding, Applied Radiation and Isotopes, Vol 107, (2016) p. 29-32.

[5] A. Ali Basheer et al., The effect of various waste materials' contents on the attenuation level of anti-radiation shielding concrete, Materials, Vol 6(10) (2013) p. 4836-4846.

[6] M. Medhat, Gamma-ray attenuation coefficients of some building materials available in Egypt, Annals of Nuclear Energy, Vol 36(6), (2009) p. 849-852.

[7] S. Mindess and J.F. Young, Concrete, Prentice-Hall, New Jersey, USA, 1981.

[8] M.F. Kaplan, Concrete radiation shielding, nuclear physics, concrete properties, design and construction, Longman Scientific \& Technical, 1989.

[9] N.A. Alsharara, Control of Radiation Levels inside the Collective Shelters, M.T.C, Cairo, 2001.

[10] ASTM C143, Standard Test Method for Slump of Hydraulic Cement Concrete, in ASTM International, PA, West Conshohocken, 2004.

[11] S. Yousef et al., Heat effect on the shielding and strength properties of some local concretes, Progress in nuclear Energy, Vol 50(1), (2008) p. 22-26.

[12] M.M. Hasan, and A. Kabir, Prediction of compressive strength of concrete from early age test result, in Proceedings of 4th Annual Paper Meet and 1st Civil Engineering Congress, Dhaka, Bangladesh, 2011. 
Military Technical College Kobry El-Kobbah, Cairo, Egypt

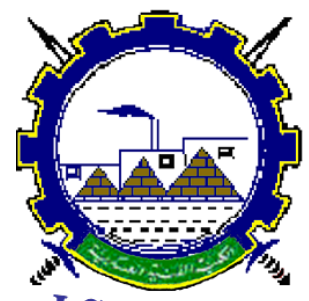

I.C.E.E.2018 $9^{\text {th }}$ International Conference on

Chemical \& Environmental Engineering

3-5 April 2018

[13] H. Beshr, A. Almusallam and M. Maslehuddin, Effect of coarse aggregate quality on the mechanical properties of high strength concrete, Construction and Building Materials, Vol 17(2), (2003) p. 97-103.

[14] Moamen.G. El-Samrah, , M.A. Abdel-Rahman, and A.M. Kany, Study Characteristics of New Concrete Mixes and their Mechanical, Physical, and Gamma Radiation Attenuation Features, Zeitschrift für anorganische und allgemeine Chemie (ZAAC), Germany, 2017.

[15] M. Földvári, Handbook of thermogravimetric system of minerals and its use in geological practice, Occasional Papers of The Geological Institute of Hungary Vol 213, Budapest, Hungary, 2011.

[16] B. Rizov, Phase transformations from goethite to hematite and thermal decomposition in various nickeliferous laterite ores, Journal of the University of Chemical Technology and Metallurgy, Vol 47(2), (2012) p. 207-210.

[17] W.M.C. McKenzie, Design of Structural Elements, Palgrave Macmillan, 2013. 
Military Technical College Kobry El-Kobbah, Cairo, Egypt

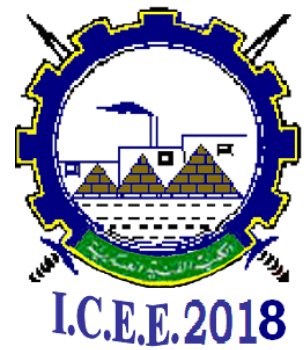

$9^{\text {th }}$ International Conference on

Chemical \& Environmental

Engineering

3-5 April 2018

Table 1: Selected physical and mechanical properties of coarse and fine aggregates.

\begin{tabular}{|c|c|c|c|c|c|}
\hline Property & Barite & Goethite & Dolomite & Limonite & Sand \\
\hline Specific gravity & 4.4 & 4.04 & 2.68 & 2.22 & 2.65 \\
\hline Water absorption, \% & 1.5 & 13.5 & 0.7 & 30.8 & 0.4 \\
\hline Crushing value, \% & 63.3 & 20 & - & - & - \\
\hline
\end{tabular}

Table 2: Chemical analysis for cement, additives and aggregates using XRF

\begin{tabular}{|c|c|c|c|c|c|c|c|c|}
\hline \multirow{2}{*}{ Oxides } & \multirow{2}{*}{ PBFSC } & \multirow{2}{*}{ SF } & \multirow{2}{*}{ FA } & \multicolumn{3}{|c|}{ Coarse aggregates } & \multicolumn{2}{|c|}{ Fine aggregates } \\
\hline & & & & Barite & Goethite & Dolomite & Limonite & Sand \\
\hline $\mathrm{SiO}_{2}$ & 23.33 & 96.81 & 61.13 & 1.16 & 11.2 & 2.24 & 16.3 & 94.84 \\
\hline $\mathrm{Al}_{2} \mathrm{O}_{3}$ & 5.91 & 0.25 & 27.68 & 0.64 & 3.39 & 0.95 & 2.97 & 2.12 \\
\hline $\mathrm{Fe}_{2} \mathrm{O}_{3}$ & 3.29 & 0.45 & 4.15 & 20.84 & 67.0 & 0.61 & 68.1 & 0.82 \\
\hline $\mathrm{CaO}$ & 57.07 & 0.16 & 1.32 & 1.59 & 6.49 & 37.9 & 4.16 & 0.52 \\
\hline $\mathrm{MgO}$ & 3.10 & 0.26 & 0.44 & 1.63 & 0.992 & 15.03 & 0.643 & 0.1 \\
\hline $\mathrm{SO}_{3}^{--}$ & 2.9 & 0.14 & 0.28 & 4.42 & 1.9 & 0.39 & 2.9 & 0.11 \\
\hline $\mathrm{Cl}^{-}$ & 0.03 & 0.03 & 0.07 & 0.41 & 0.923 & 0.13 & 0.62 & 0.06 \\
\hline $\mathrm{Na}_{2} \mathrm{O}$ & 0.24 & 0.14 & 0.15 & - & 1.46 & 0.25 & 0.985 & 0.27 \\
\hline $\mathrm{K}_{2} \mathrm{O}$ & 0.25 & 0.28 & 0.85 & 0.34 & 1.8 & 0.07 & 0.74 & 0.69 \\
\hline $\mathrm{TiO}_{2}$ & 0.08 & - & 2.07 & - & 1.49 & 0.13 & 1.28 & 0.12 \\
\hline $\mathrm{BaO}$ & - & - & 0.04 & 66.77 & - & - & - & - \\
\hline $\mathrm{P}_{2} \mathrm{O}_{5}$ & - & 0.03 & 0.61 & 0.28 & 0.91 & 0.03 & 0.83 & 0.05 \\
\hline $\mathrm{Cr}_{2} \mathrm{O}_{3}$ & - & - & - & 0.14 & 0.416 & - & - & - \\
\hline $\mathrm{MnO}$ & - & 0.05 & - & 1.1 & 0.292 & - & - & - \\
\hline $\mathrm{CeO}_{2}$ & - & - & - & - & 0.278 & - & - & - \\
\hline $\mathrm{Sm}_{2} \mathrm{O}_{5}$ & - & - & - & - & 0.314 & - & 0.168 & 0.06 \\
\hline L.O.I & 2.97 & 0.95 & 0.85 & 0.2 & 0.3 & 42.25 & 0.15 & 0.1 \\
\hline Total & 99.17 & 99.55 & 99.64 & 99.52 & 99.15 & 99.94 & 99.84 & 99.86 \\
\hline
\end{tabular}


Military Technical College Kobry El-Kobbah, Cairo, Egypt

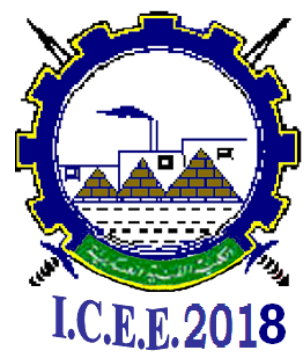

$9^{\text {th }}$ International Conference on

Chemical \& Environmental

Engineering

3-5 April 2018

Table 3: Mix proportions for the prepared concrete mixes

\begin{tabular}{|c|c|c|c|c|c|c|c|c|c|}
\hline \multirow{3}{*}{$\begin{array}{c}\text { Mixe } \\
\mathrm{s}\end{array}$} & \multicolumn{9}{|c|}{ Concrete ingredients, $\mathrm{kg} / \mathrm{m}^{3}$} \\
\hline & \multirow{2}{*}{$\begin{array}{c}\text { PBFS } \\
\text { C }\end{array}$} & \multicolumn{2}{|c|}{ Fine aggregates } & \multicolumn{3}{|c|}{ Coarse aggregates } & \multicolumn{2}{|c|}{ Additives } & \multirow{2}{*}{ S.P } \\
\hline & & Sand & Limonite & Barite & Goethite & Dolomite & $\mathrm{SF}$ & FA & \\
\hline Ba.C & 400 & 270.77 & 226.83 & 1798.3 & - & - & 50 & 50 & 12.5 \\
\hline Go.C & 400 & 270.77 & 226.83 & - & 1651.3 & - & 50 & 50 & 12.5 \\
\hline Do.C & 500 & 554.8 & - & - & - & 1126.3 & - & - & - \\
\hline
\end{tabular}

Table 4: Energies and activities of gamma radiation sources used in the measurements

\begin{tabular}{|l|c|c|c|}
\hline Property/Source & Ba-133 & Cs-137 & Co-60 \\
\hline Gamma lines $(\mathbf{k e V})$ & 356 & 662 & $1173-1332$ \\
\hline Production Date & 2014 & 2014 & 2013 \\
\hline Initial Activity $(\boldsymbol{\mu C} \mathbf{C})$ & 10 & 10 & 6.95 \\
\hline
\end{tabular}

Table 5: Some of the physical radiation properties of ${ }^{252} \mathrm{Cf}$ neutron source

\begin{tabular}{|c|c|}
\hline $\begin{array}{c}\text { Physical radiation properties of } \\
{ }^{252} \text { Cf neutron source }\end{array}$ & Values \\
\hline Alpha particle energy & $6.12 \mathrm{MeV}$ \\
\hline Effective half life & 2.65 years \\
\hline Alpha decay half life & 2.73 years \\
\hline Spontaneous fission half life & 85.5 years \\
\hline Gamma emission rate & $1.37 \times 10^{7}$ photons $/ \mu \mathrm{gm}$ \\
\hline Initial activity & $100 \mathrm{mCi}$ \\
\hline Production date & 2001 \\
\hline Average neutron energy & $2.35 \mathrm{MeV}$ \\
\hline Neutron emission rate & $1.721 \times 10^{7} \mathrm{n} / \mathrm{sec}$ \\
\hline Fission rate & $6.2 \times 10^{5} / \mathrm{sec} . \mu \mathrm{gm}$ \\
\hline
\end{tabular}


Military Technical College Kobry El-Kobbah, Cairo, Egypt

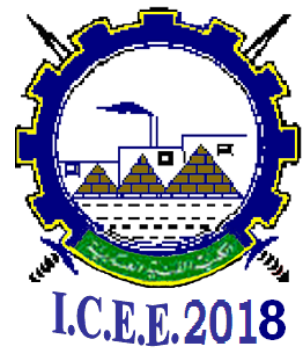

$9^{\text {th }}$ International Conference on

Chemical \& Environmental

Engineering

3-5 April 2018

Table 6: Slump values for the concrete mixes.

\begin{tabular}{|c|c|c|c|}
\hline Concrete mix & Ba.C & Go.C & Do.C \\
\hline Slump value, & 8.0 & 6.0 & 10.0 \\
\hline
\end{tabular}

Table 7: Bulk densities of the preparedconcrete mixes

\begin{tabular}{|c|c|c|c|}
\hline Concrete $\mathbf{m i x}$ & Ba.C & Go.C & Do.C \\
\hline Bulk density, $\mathbf{~ k g / \mathbf { m } ^ { 3 }}$ & 2963 & 2906 & 2570 \\
\hline
\end{tabular}

Table 8: The obtained values of mass attenuation coefficient $\left(\mu_{m}\right)$ and half value thickness (HVL) for the three concrete mixes.

\begin{tabular}{|c|c|c|c|c|c|c|c|c|}
\hline Property & \multicolumn{4}{|c|}{$\left(\boldsymbol{\mu}_{\mathbf{m}}\right), \mathbf{c m}^{2} / \mathbf{g}$} & \multicolumn{4}{c|}{ (HVL), cm } \\
\hline $\begin{array}{c}\text { Gamma } \\
\text { Energy, } \\
\text { keV }\end{array}$ & 356 & 662 & 1173 & 1332 & 356 & 662 & 1173 & 1332 \\
\hline Ba.C mix & $0.112 \pm$ & $0.088 \pm$ & $0.059 \pm$ & $0.057 \pm$ & $2.11 \pm$ & $2.67 \pm$ & $4.01 \pm$ & $4.16 \pm$ \\
& 0.006 & 0.004 & 0.003 & 0.003 & 0.083 & 0.078 & 0.152 & 0.171 \\
\hline Go.C mix & $0.088 \pm$ & $0.076 \pm$ & $0.058 \pm$ & $0.056 \pm$ & $2.73 \pm$ & $3.17 \pm$ & $4.18 \pm$ & $4.34 \pm$ \\
& 0.005 & 0.003 & 0.004 & 0.004 & 0.096 & 0.093 & 0.193 & 0.201 \\
\hline Do.C mix & $0.096 \pm$ & $0.084 \pm$ & $0.060 \pm$ & $0.057 \pm$ & $2.81 \pm$ & $3.21 \pm$ & $4.50 \pm$ & $4.75 \pm$ \\
& 0.004 & 0.004 & 0.003 & 0.003 & 0.085 & 0.097 & 0.149 & 0.165 \\
\hline
\end{tabular}

Table 9: Obtained values of $(\Sigma),(\mu)$ and (HVL) for the prepared mixes.

\begin{tabular}{|c|c|c|c|c|}
\hline $\begin{array}{c}\text { Concrete } \\
\text { mix }\end{array}$ & $(\Sigma), \mathrm{cm}^{-1}$ & $(\mu), \mathrm{cm}^{-1}$ & For fast neutrons & For total gamma \\
\cline { 4 - 5 } & & HVL, $\mathrm{cm}$ & HVL, cm \\
\hline Ba.C & $0.1051 \pm 0.005$ & $0.0918 \pm 0.002$ & $6.61 \pm 0.205$ & $7.53 \pm 0.127$ \\
\hline Go.C & $0.1119 \pm 0.004$ & $0.0823 \pm 0.005$ & $6.24 \pm 0.147$ & $8.42 \pm 0.343$ \\
\hline Do.C & $0.1030 \pm 0.004$ & $0.0797 \pm 0.002$ & $6.73 \pm 0.184$ & $8.69 \pm 0.165$ \\
\hline
\end{tabular}


Military Technical College

Kobry El-Kobbah,

Cairo, Egypt

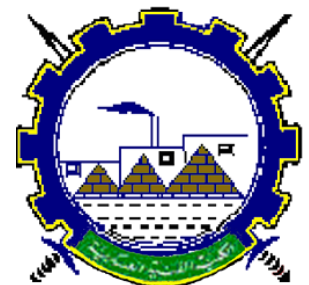

I.C.E.E.2018 $9^{\text {th }}$ International Conference on

Chemical \& Environmental

Engineering

3-5 April 2018
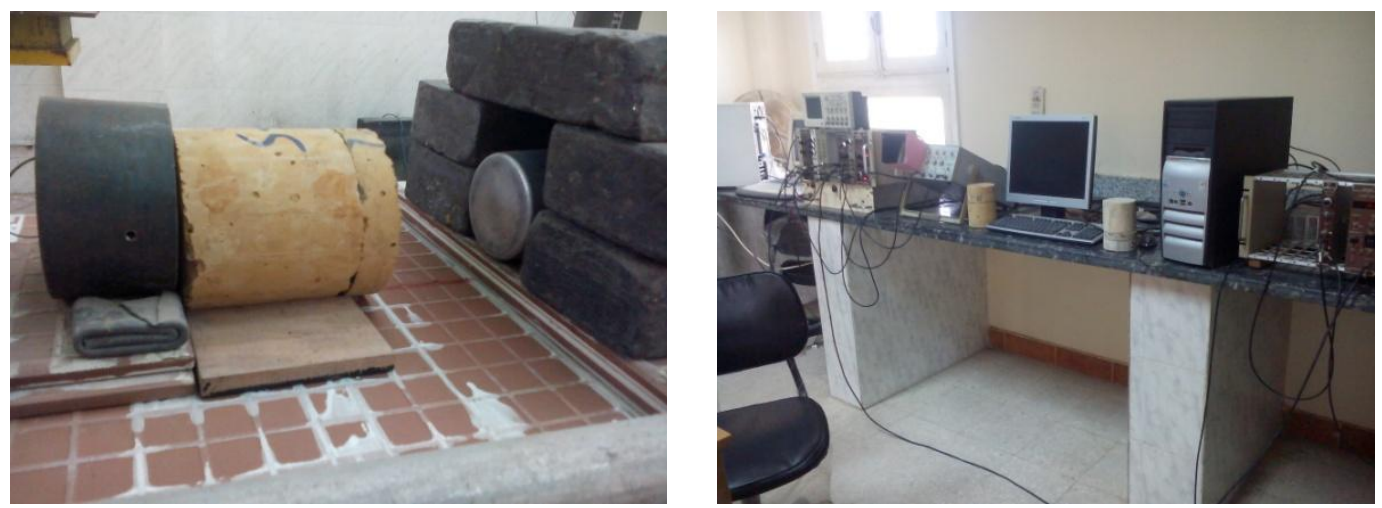

Figure 1: Photo image for fast neutrons attenuation measurements including electronics associated with the stilbene detector.

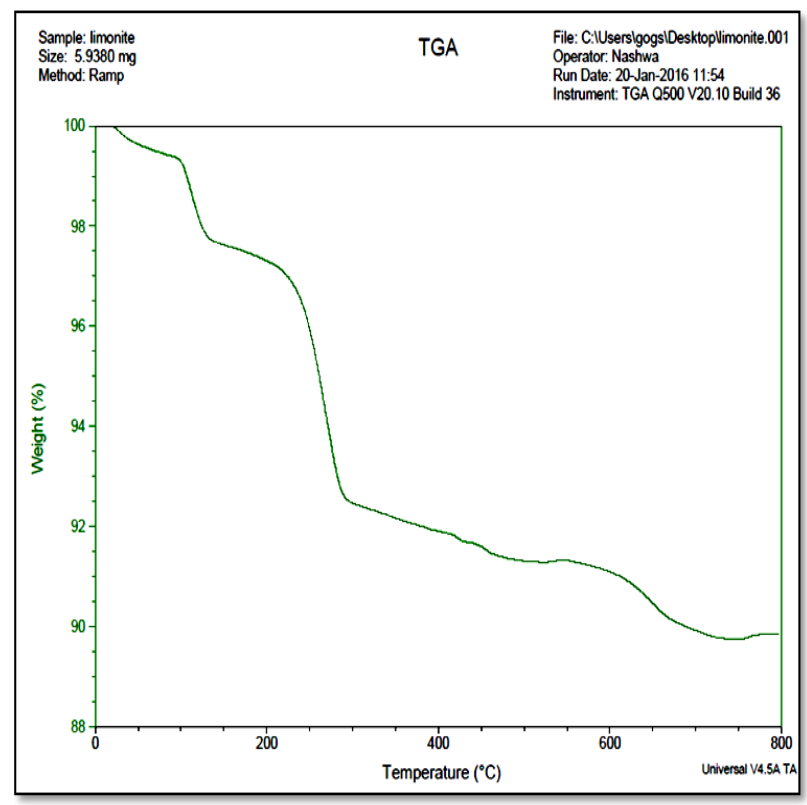

Figure 2: TGA pattern for limonite ore. 


\begin{tabular}{|l|l|}
\hline Proceeding of the $9^{\text {th }}$ ICEE Conference 3-5 April 2018 & NRA \\
\hline
\end{tabular}

Military Technical College

Kobry El-Kobbah,

Cairo, Egypt

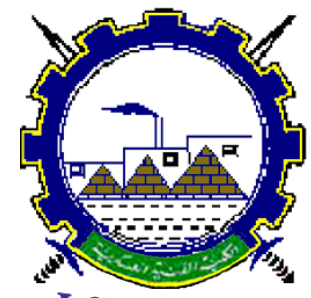

I.C.E.E.2018 $9^{\text {th }}$ International Conference on

Chemical \& Environmental

Engineering

3-5 April 2018

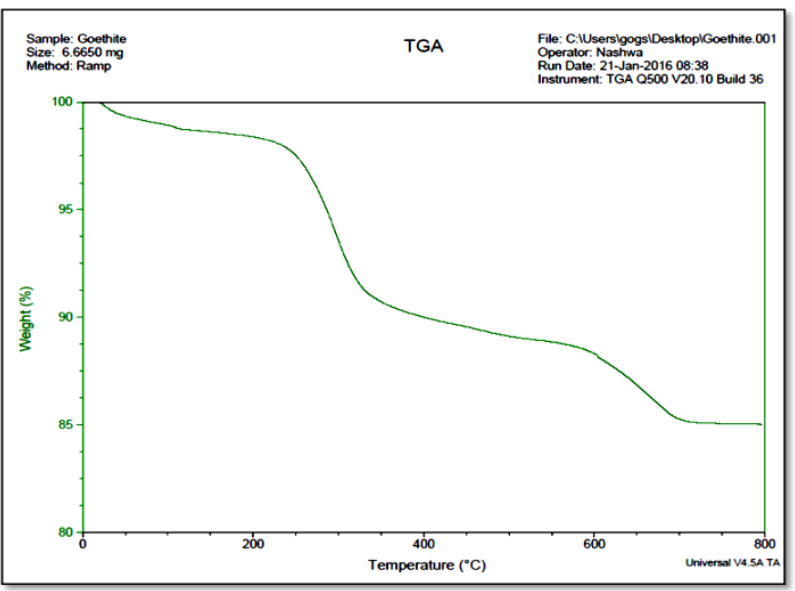

Figure 3: TGA pattern for goethite ore.

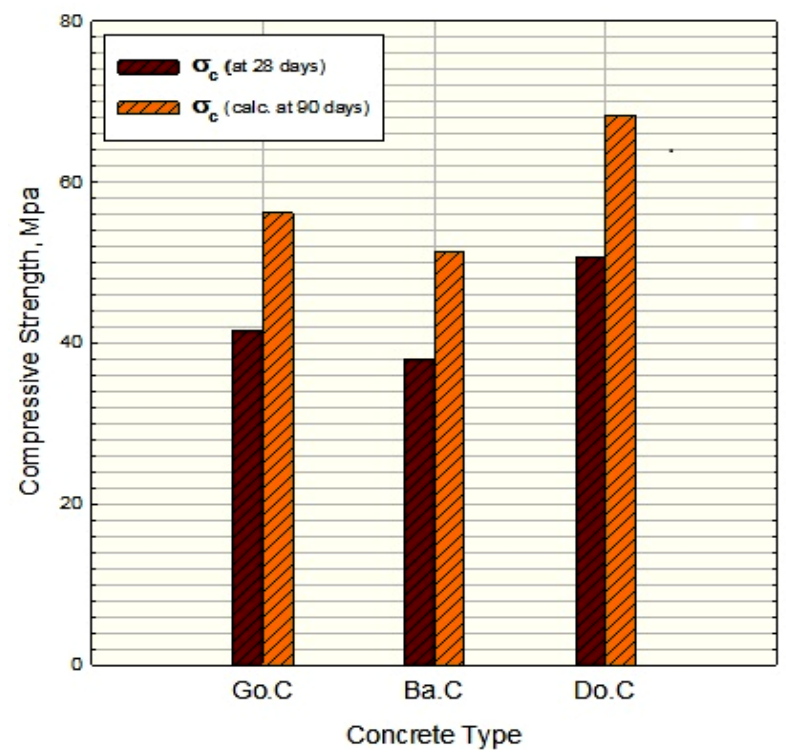

Figure 4: Compressive strength at room temperature for the prepared mixes. 
Military Technical College Kobry El-Kobbah, Cairo, Egypt

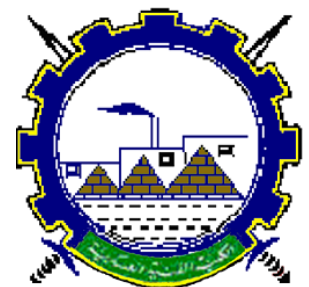

I.C.E.E.2018 $9^{\text {th }}$ International Conference on

Chemical \& Environmental

Engineering

3-5 April 2018

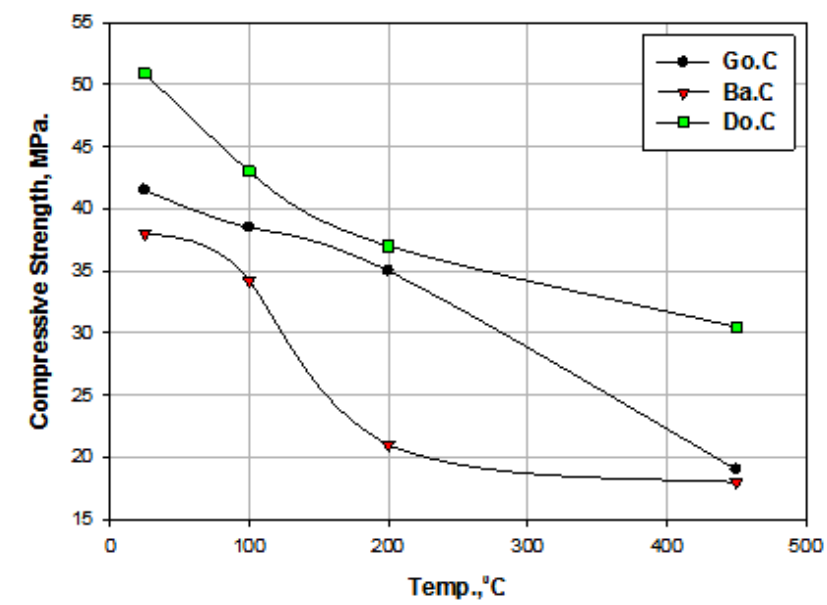

Figure 5: Compressive strength values for prepared concrete mixes at different temperatures.

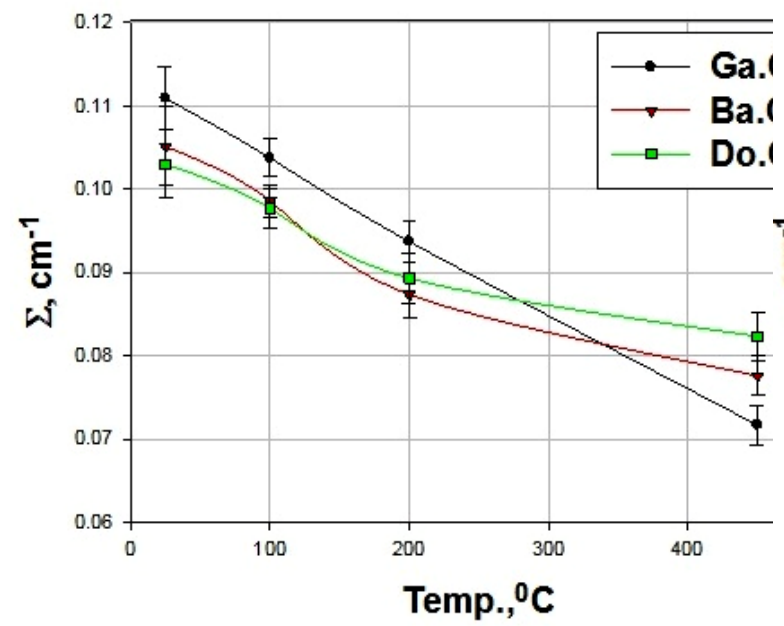

Figure 6: Fast removal cross section of neutrons for concrete mixes at different temperatures.

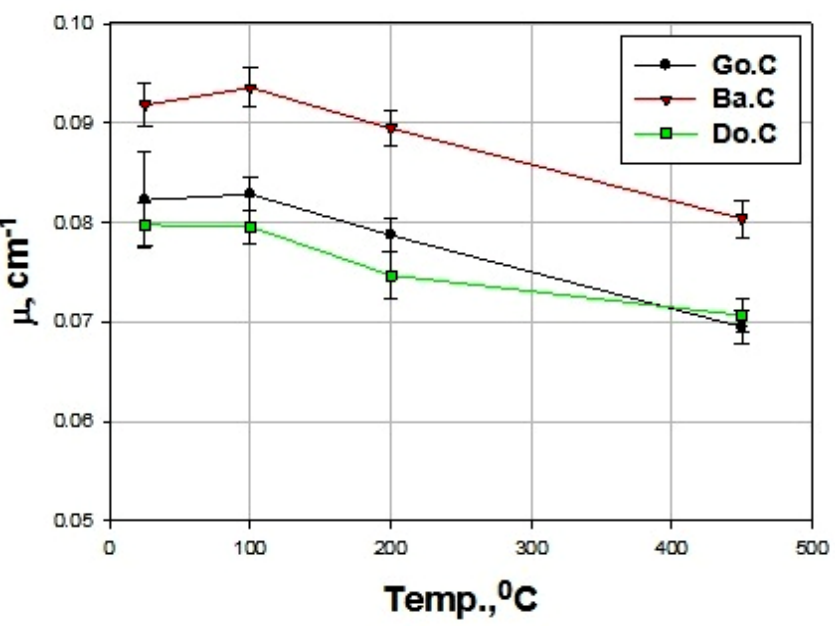

Figure 7: Linear attenuation coefficient of total gamma rays for the mixes at different temperatures. 